\title{
Limits to the potential distribution of light brown apple moth in Arizona-California based on climate suitability and host plant availability
}

\author{
Andrew Paul Gutierrez • Nicholas J. Mills • \\ Luigi Ponti
}

Received: 21 July 2009/ Accepted: 29 January 2010/Published online: 20 February 2010

(C) The Author(s) 2010. This article is published with open access at Springerlink.com

\begin{abstract}
The highly polyphagous light brown apple moth (LBAM) (Epiphyas postvittana (Walk.): Tortricidae) is indigenous to Australia and was first found in California in 2006. It is currently found in 15 coastal counties in California, but nowhere has it reached outbreak status. The USDA projects the geographic range of LBAM will include much of Arizona and California and the southern half of the US, which together with economic estimates of potential crop losses have been used as the rationale for an eradication program in California. We report a temperature-driven demographic model to predict the likely distribution and relative abundance of LBAM
\end{abstract}

A. P. Gutierrez · N. J. Mills

Department of Environmental Science Policy and Management, College of Natural Resources, University of California, Berkeley, CA 94720-3114, USA

A. P. Gutierrez · L. Ponti

Center for the Analysis of Sustainable Agricultural Systems (CASAS Global), 37 Arlington Ave, Kensington, CA 94707, USA

L. Ponti

ENEA, Dipartimento BAS, Gruppo "Lotta alla Desertificazione", S.P. Anguillarese 301, 00123

S. Maria di Galeria (Rome), Italy

A. P. Gutierrez $(\bowtie)$

Ecosystem Science, University of California, 137 Mulford Hall, Berkeley, CA 94720, USA

e-mail: casas.global@berkeley.edu using the detailed biology reported by Danthanarayana and colleagues, and climate data from 151 locations in California and Arizona for the period 1995-2006. The predictions of our model suggest that the near coastal regions of California are most favorable for LBAM, the northern Central Valley of California being less favorable, and the desert regions of Arizona and California being unfavorable. The model also predicts that LBAM populations can develop at two of the hottest locations in SE Australia where it is has long been known to occur. This reassessment of the potential distribution of LBAM in California and Arizona suggests that its likely ecological and economic impacts would be less than previously assessed by USDA and that its current pest status warrants re-evaluation.

Keywords Light brown apple moth .

Geographic distribution - Invasive species ·

Eradication · Modeling · GIS

\section{Introduction}

The light brown apple moth (LBAM, Epiphyas postvittana (Walk.): Tortricidae) is indigenous to Australia where it is considered a pest of pome fruits and grape, but it has been recorded from a broad range of host plant species including crops, ornamentals and herbaceous weeds (Danthanarayana 1975; Geier and Briese 1981; Suckling and Brockerhoff 2010). This 
pest was accidentally introduced into England, Hawaii, New Caledonia and New Zealand, and was first found in the San Francisco Bay area by University of California Emeritus Professor Jerry Powell in 2006 (Brown 2007). LBAM is currently found in 15 coastal and near coastal counties in California suggesting it has been present in the state for several years. To date the pest has not reached outbreak status at any location in California.

The United States Department of Agriculture (USDA) posits that the potential distribution of LBAM includes all areas having sufficient thermal units for the completion of three generations (i.e., California and the Southern half of the United States) with estimated losses of $\$ 118$ million per annum from apple, grape, orange and pear production (Fowler et al. 2009). In response to this perceived threat, the USDA considers LBAM to be an actionable quarantine pest, and has placed quarantine on California produce in affected counties as well as all counties in Hawaii (Federal Quarantine Order of May 2, 2007). In late 2007, the California Department of Agriculture (CDFA) began an eradication program using pheromones, sprays and other techniques. The pheromone spray program engendered considerable public protest concerning claimed public health effects, the lack of hard evidence that LBAM is a serious pest and the proposed expenditure of nearly 100 million dollars for the program in California alone. Because of public outcry, an eradication program based on the sterile insect technology (SIT) has now been proposed.

The potential ecological and economic impact of invasive species can be influenced by many factors (Parker et al. 1999; Levine et al. 2003; Buckley 2008), but for invasive arthropod pests, climate and temperature in particular have played a central role in the assessment of risk (e.g., Fowler et al. 2009; Migeon et al. 2009; Sutherst and Bourne 2009). A variety of climate matching models have been used to predict the potential distribution of invaders (Coetzee et al. 2009; Rodda et al. 2009; Sutherst and Bourne 2009), but there have been few attempts to include biotic interactions in addition to abiotic drivers into such models (e.g., Gutierrez and Baumgärtner 1984; Gutierrez et al. 2008). Here, we analyze the potential distribution of LBAM in Arizona and California using a temperature-driven demographic model to provide a more quantitative and realistic approach for assessment of the risk of this invasive pest.

\section{Biology of light brown apple moth}

Danthanarayana (1975) reviewed the sparse literature on the biology of LBAM prior to 1975 (Dumbleton 1932, 1939; Evans 1937; Geier 1965; Lawrence and Bartell 1972; Bartell and Lawrence 1973; MacLellan 1973). In a series of papers, Danthanarayana (1975, 1976a, b, c), Danthanarayana et al. (1995), Gu and Danthanarayana (1990a, b, 1992) described the biology of LBAM, and this body of work is the basis for our analysis. The developmental biology of E. postvittana is summarized below and in Figs. 1 and 2.

Light brown apple moth does not have a diapause period and feeds on numerous plant species across family lines; the lower threshold for development of all stages was estimated as $7.5^{\circ} \mathrm{C}$ (Danthanarayana 1975), but reanalysis of the data for eggs and larvae yields a non linear relationship with a slightly lower threshold of $6.8^{\circ} \mathrm{C}$ (Fig. 1). The mean duration of the egg stage is 5.7 days at $28^{\circ} \mathrm{C}\left(120.8\right.$ degree days; $\left.d d_{>6.8^{\circ} \mathrm{C}}\right)$ with no eggs hatching above $31.3^{\circ} \mathrm{C}$. Larval and pupal developmental times are 335 and $142 d d$, respectively with an upper threshold for development for larvae and pupae of approximately $31.5^{\circ} \mathrm{C}$. The generation time is $594 d d$. Fifty-percent of eggs are laid by $646 d d$; mean

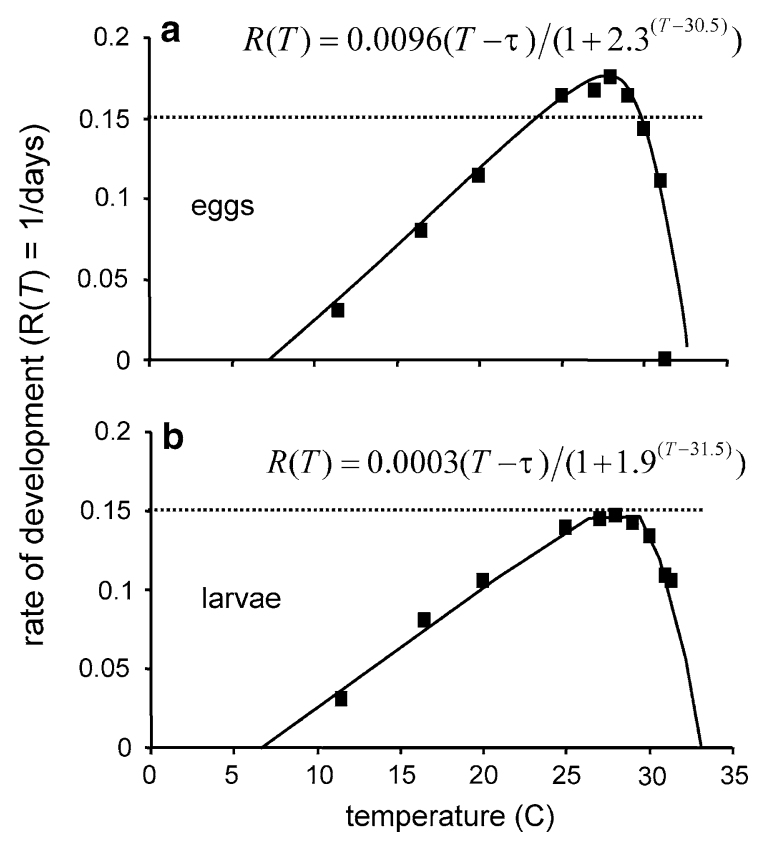

Fig. 1 The effect of temperature $(T)$ on the developmental rates of LBAM eggs (a) and larvae (b) (data from Danthanarayana 1975) 
Fig. 2 The effects of LBAM adult age and daily average temperature $(T)$ on fecundity: a per capita daily fecundity on female age $(x)$ at $20^{\circ} \mathrm{C}$, b a scalar $\left(0 \leq \phi_{T} \leq 1\right)$ of the effects of average temperature on fecundity, c the combined effects of subfigures $\mathbf{a}, \mathbf{b}$ (data from Danthanarayana 1975), and the effects of extreme temperature $\mathbf{d}$ on the mortality rate per day $\left(0 \leq \mu_{T} \leq 1\right)$. Note that the symbol (filled circle) represents data and (open circle) represents linear extrapolations
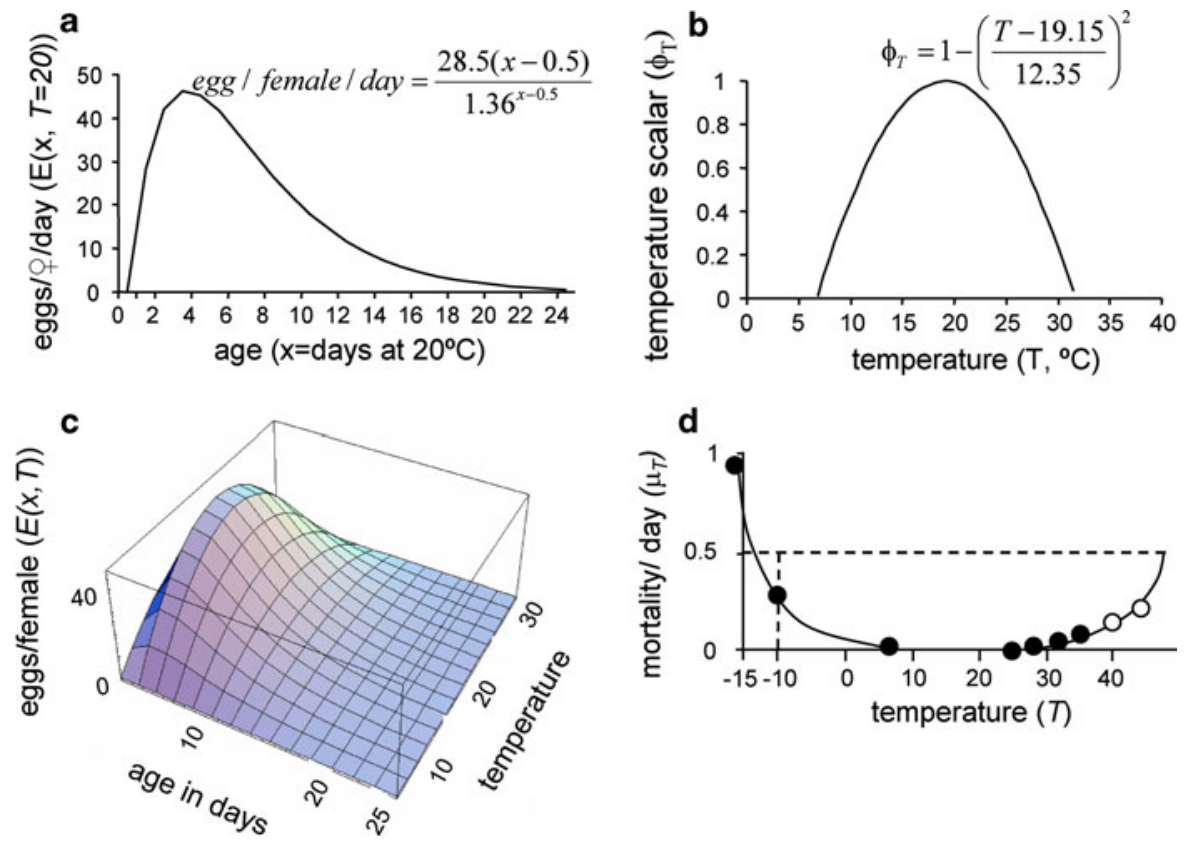

fecundity is approximately 384 but varies considerably (0-1492) with female size, larval food and temperature (Danthanarayana et al. 1995; Gu and Danthanarayana 1990a, b, 1992), but only temperature is used in the model. The optimum temperature for oviposition is near $20^{\circ} \mathrm{C}$. At constant temperatures of 20 and $25^{\circ} \mathrm{C}$, $>50$ and $80 \%$ of the eggs are laid by the fourth and the seventh day after emergence respectively with peak oviposition occurring when adult females are 2-3 days old. Body weight of both male and female moths at emergence increases with increasing temperature up to $25^{\circ} \mathrm{C}$. Danthanarayana $(1976 \mathrm{a}, \mathrm{b}, \mathrm{c})$ provides information on the diel and lunar periodicities, seasonal variation in flight activity and the influence of food and temperature on flight performance in the field. Flight duration increases with temperature in the range $15-28^{\circ} \mathrm{C}$, with males being stronger fliers than females with the longest flights occurring on day four. Mating in females begins within $24 \mathrm{~h}$ of emergence with nearly all being mated within 4 days. The average number of matings is 2 , although by day 11 some females may mate as many as five times ( $\mathrm{Gu}$ and Danthanarayana 1990a, b, 1992). Geier et al. (1978) found that a small proportion of LBAM females produce predominantly female progeny resulting in the proportion of males in field samples to range from 0.43 to 0.45 . Based on LBAM's biology, theoretical considerations suggest that this value is near the theoretical optimum assuring that nearly all females are mated (see Geier et al. 1978). The resulting sex ratio in our model is 1.1 $: 0.9 \mathrm{o}$.

Data from Danthanarayana (1975) were used to estimate the effects of adult age and temperature on per capita fecundity (Fig. 2a-c). The data are illustrated in days for ease of interpretation, but all calculations in the model are made in physiological time units. The effect of temperature $(T)$ and age $(x)$ on per capita daily fecundity is modeled as the product of the function for maximum fecundity $\left(E\left(x, T_{\text {opt }}\right)\right)$ at the optimum temperature $\left(T_{\text {opt }}=20^{\circ} \mathrm{C}\right.$, Fig. $\left.2 \mathrm{a}\right)$ and a scalar function of the effects of temperature above and below the optimum $\left(\phi_{T}\right.$, Fig. 2 b) yielding $E(x, T)=$ $\phi_{T}(T) \cdot E\left(x, T_{\text {opt }}\right)$ (Fig. 2c). The rightward displacement of the fecundity function from the $y$-axis (Fig. 2a, c) reflects the short pre-oviposition period.

\section{Sources of mortality}

Three sources of LBAM mortality are included in the model: (1) Intrinsic mortality in the favorable range between 6.8 and $28^{\circ} \mathrm{C}$ is accounted for by the differing progression of the population members with temperature through the distributed maturation time model, (2) mortality due to extremes of temperatures, and (3) mortality due to the combined action of 
natural enemies and other factors. Only mortality sources (2) and (3) require further explanation.

\section{Extremes of temperature}

Data on the lethal effects of low temperature on LBAM are sparse, and hence we used estimates from an ongoing study by Buergi and Mills (unpublished observations) showing that $30 \%$ of larvae die within 1 day at $-10^{\circ} \mathrm{C}$ and all larvae died within 1 day at $-16^{\circ} \mathrm{C}$. We computed the daily mortality rate from low temperatures as the integral of time and temperature below the developmental threshold $\left(\mu_{T}\right.$; Eq. 1i; Fig. 2d; Gutierrez et al. 2005), and used it to model the daily over-wintering mortality rate.

$$
\begin{aligned}
& \text { if } T_{\min }<6.8^{\circ} \mathrm{C}, 0.01<\mu_{T}=1 \\
& \quad-0.015 \exp \left(0.323 d d_{<6.8^{\circ} \mathrm{C}}\right)<1 \quad \mathrm{i} \\
& \text { if } T_{\max }>28^{\circ} \mathrm{C}, 0.01<\mu_{T}=1 \\
& \quad-0.125 \exp \left(0.025 d d_{>28^{\circ} \mathrm{C}}\right)<1 \quad \text { ii } \\
& \text { else } \mu_{T}=0
\end{aligned}
$$

The daily mortality rate at high average temperatures (Eq. 1ii) was estimated from data in figure 11 in Danthanarayana (1975) showing the percent survivorship from egg hatch to adult emergence at several temperatures $(T)$. The daily proportional mortality was computed from the percent mortality at the four highest temperatures shown in the figure by dividing by the egg to adult period $(477.5 d d)$, multiplying by the $d d_{>6.8^{\circ} \mathrm{C}}$ at each temperature $(T)$, and dividing by 100 . The mortality rate increases with average daily temperature above $28-45^{\circ} \mathrm{C}$ (Eq. 1ii, Fig. 2d). Mean daily temperatures above $45^{\circ} \mathrm{C}$ are unlikely to be encountered in the field.

\section{Other mortality}

Field life table studies summarized by Danthanarayana (1983) in Victoria, Australia estimate the action of various mortality factors affecting LBAM life stages. Total generation mortality was approximately 98-99.5\% with egg mortality being a key factor during spring and autumn, and egg mortality and losses of first instar during dispersal being key factors during summer. Predation of eggs and first instar larvae by generalist predators acting in a density independent manner increased with hot dry weather and nearly eliminated summer generations. Similar high rates of mortality were also observed by Geier and Briese (1980) including widespread nuclear polyhedrosis virus infection (Geier and Briese 1979).

Despite having been present in California for several years, LBAM has failed to reach outbreak levels, even though it has invaded a Mediterranean climate similar to that of SE Australia. Recent field observations in California have also shown that the egg and larval stages of LBAM are attacked by a suite of generalist predators and parasitoids (NJ Mills, unpublished observations). In the absence of field life tables for LBAM in California, we take a composite approach to incorporating this mortality in a manner that reflects the population levels of LBAM observed in the invaded areas. We develop a functional response model (Eq. 2) wherein the daily proportional mortality $\left(\mu_{\mathrm{c}}\right)$ increases with both temperature $\left(\Delta t=d d_{>6.8^{\circ} \mathrm{C}}\right)$ and prey density $\left(N_{\text {eggs }}+\right.$ $\left.N_{\text {larvae }}\right)$ at a decreasing rate. The coefficient 0.0025 in Eq. 2 is the proportion of eggs and larvae attacked $d d^{-1}$, and was chosen iteratively to produce the low population levels that are currently observed in the field.

$0 \leq \mu_{\mathrm{c}}=1-\mathrm{e}^{-0.0025\left(N_{\text {eggs }}+N_{\text {larvae }}\right) \Delta t}<1$

\section{Rainfall}

Rainfall can have an important indirect effect on LBAM dynamics through host plant availability. Outside of irrigated crops, herbaceous weedy plants are important hosts for LBAM, and as it is an insect with no winter diapause these are often the only host plants available for the period from late summer through spring (Geier and Briese 1981). To examine the effect of rainfall on annual host plant distribution and consequently the potential distribution of LBAM, we use the well-studied drought tolerant Mediterranean yellow starthistle (Centaurea solstitialis L.; YST) as a surrogate annual plant species (see Gutierrez et al. 2005).

\section{Model overview}

The biology of LBAM is embedded in an Erlang distributed maturation time demographic model that 
simulates the dynamics of an age structured population (Vansickle 1977; DiCola et al. 1999, p. 523524). The general model for the $i$ th age class of a population is:

$\frac{\mathrm{d} N_{i}}{\mathrm{~d} t}=\frac{k \Delta x}{\Delta}\left[N_{i-1}(t)-N_{i}(t)\right]-\mu_{i}(t) N_{i}(t)$.

$N_{i}$ is the abundance of the $i$ th age class, $d t$ is the change in time ( $d d /$ day computed using the non linear model), $k$ is the number of age classes, $\Delta$ is the expected mean developmental time, $\Delta x$ is a daily increment of age, and $\mu_{i}(t)$ includes the proportional net loss rate of births as modified by temperature and age (Fig. 2c), the death rate due to extremes of temperature ( $\mu_{T}$, Eq. 1) and to composite mortality effects $\left(\mu_{c}\right.$, Eq. 2).

All life stages can be included in one dynamics model with eggs produced by the adult age classes entering the first age cohort $\left(N_{1}(t)\right)$ as $x_{0}(t)$ and the survivors exiting at maximum age as $y(t)$ (Fig. 3a). The flow rates $\left(r_{i}(t)\right)$ between age classes depends on the numbers in the previous age class (Fig. 3a) and $\mathrm{d} t$. The distribution of final maturation times (Fig. 3b) is determined by the number of age classes, the mean maturation time $\Delta$ and the variance of maturation times (var) $\left(k=\Delta^{2} /\right.$ var). The larger the value of $k$, the narrower is the Erlang distribution of developmental times. The variance of developmental times reported by Danthanarayana (1975) was large and a value of $k=15$ was selected to reflect this biology.

For convenience, separate models are used for the egg, larvae, pupae and adults stages $\left(\mathrm{S}_{i=\mathrm{egg}}\right.$, larval, pupa, adult $)$ each having stage-specific characteristics (e.g. $\Delta_{l}, k_{l}, \ldots$ ) with the outflow of the last age class of a stage $\left(y_{i}(t)\right)$ entering the first age class of the next stage $\left(x_{i+1, o}(t)\right)$, and all eggs produced by the adult stage entering the first age class of eggs as $x_{0}(t)$ (Fig. 3c). The model parameters are reported in Table 1.

\section{Simulation and GIS}

Daily weather data (maximum and minimum temperatures, solar radiation, precipitation, $\mathrm{RH}$ and runs of wind) for the period 1 January 1995 to 15 November 2006 from 151 locations across California and Arizona (Fig. 4a) were used in across year simulations. An initial population density of 50 first instar larvae $\mathrm{m}^{-2}$ was assumed at all locations in California and Arizona and the simulations were run
Fig. 3 The distributed maturation time model: $\mathbf{a}$ all life stages, $\mathbf{b}$ the frequency distribution of maturations times with different numbers of age classes $(k)$ and $\mathbf{c}$ separate models for each life stage each having flow biology depicted in $\mathbf{a}$
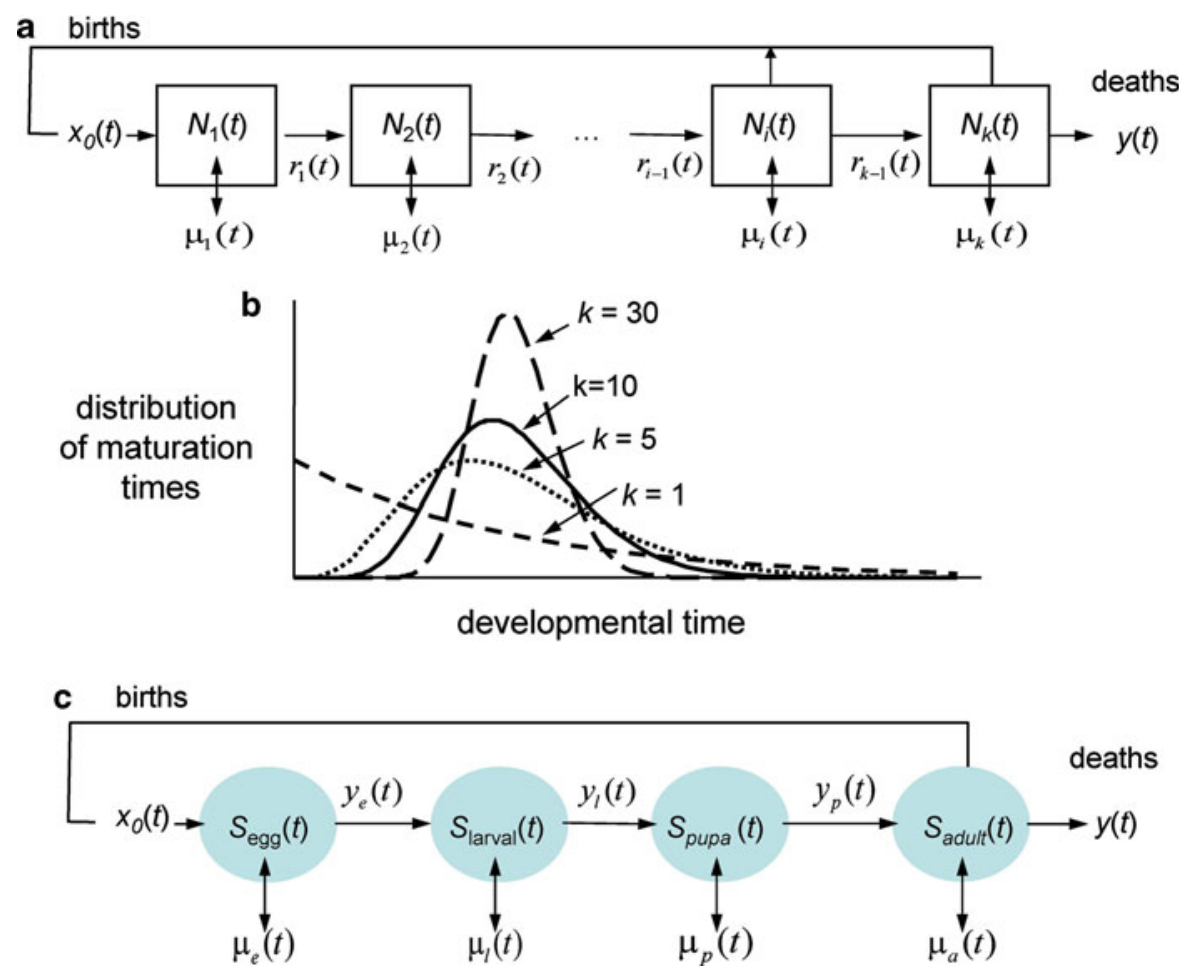
Table 1 Biological parameters for the light brown apple moth
Fig. 4 Weather stations used in the regional study (a), and maximum and minimum temperatures and simulation dynamics of LBAM egg and larval dynamics at Salinas (b, c) and Davis, California (d, e) during $1 / 1 / 2005$ and $15 / 10$ / 2006. The lower $\left(6.8^{\circ} \mathrm{C}\right)$ and upper $\left(28^{\circ} \mathrm{C}\right)$ thresholds below and above which temperature mortality accrues are shown as dashed lines in sub figs. $\mathbf{b}$ and $\mathbf{d}$. The location of Salinas (open circle) and Davis (filled circle) are illustrated in $\mathbf{a}$

\begin{tabular}{lll}
\hline Process & Parameter/eqn & Light brown apple moth \\
\hline Thermal threshold $\left(\right.$ in $\left.{ }^{\circ} \mathrm{C}\right)$ & $\tau$ & $6.8^{\circ} \mathrm{C}$ \\
Daily degree days & $\Delta d d(t)$ & \\
$335.3 \times\left(0.0003(T-\tau) /\left(1+1.9^{(T-31.5)}\right)\right)$ & & \\
Duration of life stages in degree days at $20^{\circ} \mathrm{C}$ & $d d$ & Egg $(120.8)$ \\
& & Larvae $(335.5)$ \\
& & Pupa $(142.0)$ \\
Maximum age $(x)$ per capita fecundity/ & $a$ & Adult $(290.4)$ \\
day at age $x$ and temperature $T$ & $b$ & 28.50 \\
$F(x, T)=\phi(T) \cdot a(x-0.5) / b^{x-0.5}$ & & 1.36 \\
$\phi(T)=1-\left[\frac{\left(T-T_{\min }-T_{\text {mid }}\right)}{T_{\text {mid }}^{2}}\right]^{2}$ & $T_{\min }$ & \\
Sex ratio & $T_{\max }$ & $6.8^{\circ} \mathrm{C}$ \\
Delay parameter & $T_{\operatorname{midx}}$ & $31.50^{\circ} \mathrm{C}$ \\
\hline
\end{tabular}

a
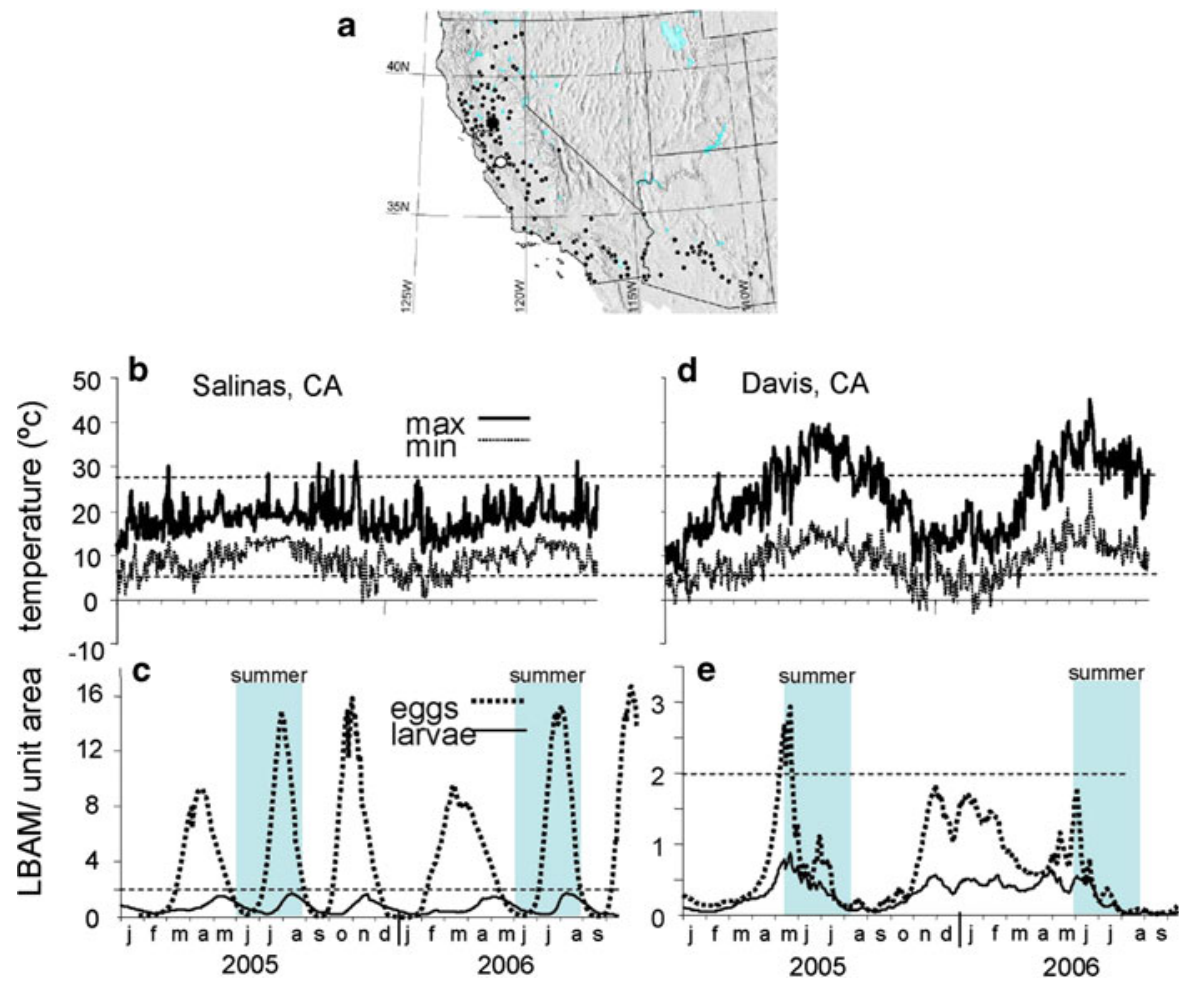

continuously over the 1995-2006 period. Data from the first year of simulation were not included in the analysis to allow populations to adjust to the effects of site-specific weather.

Data from the simulation for all locations were georeferenced and written to files for mapping at elevations below $1,000 \mathrm{~m}$. The open source geographic information system (Grass GIS) originally developed by the United State Army Corp of Engineers was used to map the data (Geographic Resources Analysis Support System (GRASS) Software, ITC-irst, Trento, Italy (http://grass.itc.it)). Raster-based triangulation kriging on a one $\mathrm{km}$ grid was used to interpolate the simulation data. The cumulative larval days per year 
from the simulation was used as an index of the favorability of the climate for the occurrence of LBAM at a particular location. This index should not be considered a prediction of either absolute population densities of LBAM or potential damage caused by LBAM at a particular location. Its purpose is merely to reflect the favorability of the climate for LBAM population growth.

Three simulation analyses were performed:

1. The relative abundance and phenology of LBAM under mild conditions of Salinas, CA and more extreme conditions common to Davis, CA to show the effects of temperature assuming non limiting host plant availability.

2. A regional analysis of the favorability of temperature for LBAM across all locations in California and Arizona assuming non limiting host plant availability.

3. A regional analysis of climatic favorability for LBAM using the limiting effect of rainfall on a surrogate annual plant to illustrate the potential effects of rainfall on the availability of weedy host plants for LBAM in California and Arizona.

\section{Results}

Simulation for Salinas and Davis, CA

Simulations of egg and larval population dynamics using observed maximum and minimum temperatures at Salinas, Monterey County in coastal Northern California and Davis, Yolo County in Central California (Fig. 4) were conducted for the period 1 January 2005 to 15 October 2006 to illustrate the effects of differing climatic temperatures on the relative abundance and phenology of LBAM. Temperatures in Salinas were generally mild throughout the year (Fig. 4b) allowing the development of three generations (Fig. 4c). In contrast, temperatures at Davis were colder during winter though rarely freezing, while summers were often very hot (Fig. 4d). The resulting generations at Davis are less distinct (Fig. 4e) with extremes of temperature reducing fecundity and increasing mortality and restricting population growth to the milder times of the year. Consequently the relative abundance of egg and larval populations at Salinas were predicted to be six and two fold greater, respectively than those at Davis.

Regional analysis: influence of temperature with non-limiting host plants

A map of the locations where LBAM adults have been caught in pheromone traps was reported in Fowler et al. (2009) (Fig. 5a). The moth catches are concentrated in the San Francisco and Monterey Bay areas, but some catches have occurred in coastal regions of southern California.

Mean larval-days year ${ }^{-1}$ for the period 1996-2006 is used as an index of LBAM favorability with respect to temperature for regional mapping (Fig. 5b). The
Fig. 5 GIS mapping of average simulated light brown apple moth populations (larval days during 1996-2005) in Arizona and California: a locations where the moth has been recovered in northcentral California (from Fowler et al. 2009) and $\mathbf{b}$ the simulated average distribution below $750 \mathrm{~m}$

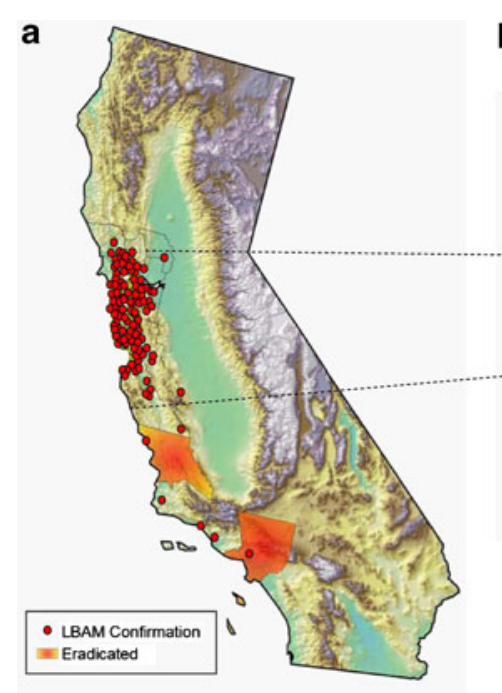

b

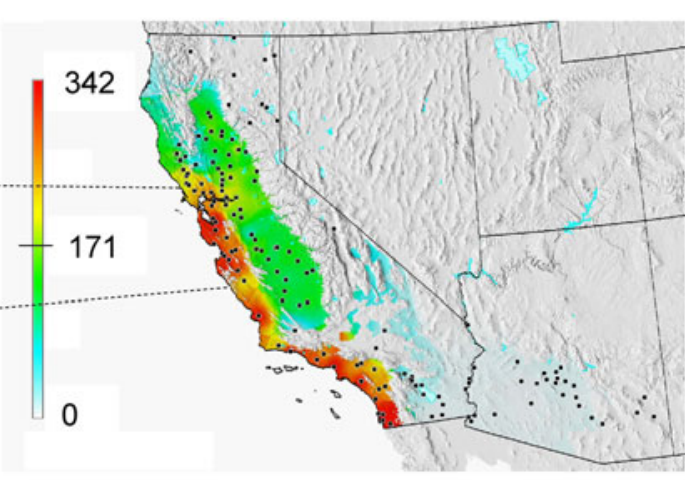

cumulative larval days $\mathrm{y}^{-1}$ (mean) 
simulation shows good correspondence between the predicted distribution of LBAM and the recorded trap catches in California, especially in the San Francisco and Monterey Bay areas. The model also suggests that the potential distribution of LBAM could extend southward along the coastal into Southern California (Fig. 5b, areas of red-orange-yellow), and eastward from San Francisco Bay into parts of the Central Valley (e.g., Davis) where areas of intermediate favorability (yellow) are created by the moderating influence of easterly ocean breezes during summer. These areas of intermediate to high favorability include some important apple, pear and grape growing regions of California. In contrast, most of the Central Valley shows low to intermediate favorability (green), while the desert valleys of Southern California and the deserts of Arizona are predicted largely unfavorable because of very high summer temperatures that reduce fecundity and increase mortality (very light blue to absence of color).

The regional simulation data were analyzed using a multiple linear regression (Eq. 4) to assess the relative influence of high and low extremes of temperature on the index of favorability. The dependent variable was regressed on cumulative yearly $d d_{>6.8^{\circ} \mathrm{C}}, d d_{>28^{\circ} \mathrm{C}}$ and $d d_{<6.8^{\circ} \mathrm{C}}$ together with their interactions and only those variables and interactions with slopes significantly different from zero $(P<0.01)$ were retained in the final model:

$$
\begin{aligned}
& \text { larval days }=251.09-0.223 d d_{<6.8^{\circ} \mathrm{C}} \\
& \quad-0.297 d d>28^{\circ} \mathrm{C}-0.0007 d d_{<6.8^{\circ} \mathrm{C}} \times d d_{>28^{\circ} \mathrm{C}} \\
& n=1490, \quad R^{2}=0.80, \quad F=1989.2
\end{aligned}
$$

These results show that on average, $d d_{>28^{\circ} \mathrm{C}}$ had a $33 \%$ greater marginal effect on the index of favorability than $d d_{<6.8^{\circ} \mathrm{C}}$ (i.e. $\partial y / \partial d d>28^{\circ} \mathrm{C}>\partial y / \partial d d_{<6.8^{\circ} \mathrm{C}}$ ).

The assumption of this analysis is that host plant availability is not limiting, but this is obviously not the case as experience from Australia shows that annual plants are an integral component of the LBAM life system (Geier and Briese 1981).

Regional analysis: influence of temperature and rainfall-limited host plants

Many Mediterranean annual plants germinate during fall and early winter periods of rain and favorable temperatures. For these plants to persist without irrigation, sufficient rainfall for them to grow and produce seed must occur. The invasive yellow starthistle (YST) is used here to illustrate the potential effect of host plant availability on the distribution of LBAM. YST occurs widely in California except in the southern half of the Central Valley and the desert regions of Arizona and California (Fig. 6a) where it is limited by low variable rainfall that on average is below the $350 \mathrm{~mm}$ isohyets (Fig. 6b) (see Gutierrez et al. 2005). The combined effects of temperature and limiting rainfall for annual host plants on the potential distribution of LBAM may be viewed by overlaying Fig. $6 \mathrm{~b}$ on Fig. 5b yielding Fig. 6c. The combination of the two factors reinforces the conclusion that the potential distribution of LBAM is largely near coastal with some extension into the Sacramento Valley. Its distribution in Southern California and the deserts of Arizona is likely to be limited by both high summer temperatures and low levels of precipitation across much of the region, with temperature alone as the limiting factor in irrigated crops.

\section{Discussion}

Exotic pests are thought to cause losses in excess of $\$ 137$ billion annually in the US (Pimentel et al. 2000), and potential losses due to light brown apple moth are estimated to be $\$ 118$ million per annum for apple, grape, orange and pear crops across the USA (Fowler et al. 2009). LBAM is not the first exotic leafroller to invade California; the Palearctic species Acleris variegana (Schiffermüller) and Cnephasia longana (Haworth) remain confined to coastal regions after 90 and 60 years, respectively, while the Mexican species Platynota stultana (Walsingham) took 50 years to spread from southern California into Central California where it is considered a secondary pest of grape (Powell 1983, 1997, and personal communication). Leaf rollers are generally not considered primary pests of agricultural crops, and while many, including LBAM, have the potential to have direct impact by grazing on the surface of fruit or facilitating Botrytis infection within grape clusters, they remain classified as secondary pests due to their amenability to integrated pest management. The experience in New Zealand where LBAM is also an invasive pest and where climatic conditions of temperature and rainfall are conducive to LBAM population development, serves as a valuable example of how its damage can be readily managed as part of an 
Fig. 6 The added indirect effects of rainfall on LBAM distribution: a the simulated average distribution of yellow starthistle in California (see Gutierrez et al. 2005), b the distribution of average total rainfall greater than $350 \mathrm{~mm}$ at elevations below $1,000 \mathrm{~m}$, c superimposing total rainfall $>350 \mathrm{~mm}$ on the simulated distribution and abundance of LBAM based only on temperature
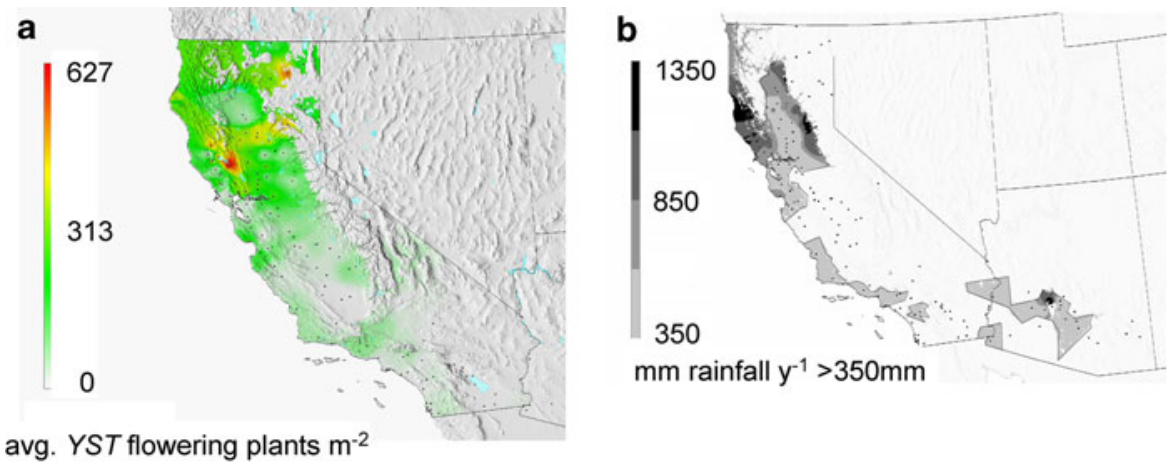

avg. YST flowering plants $\mathrm{m}^{-2}$

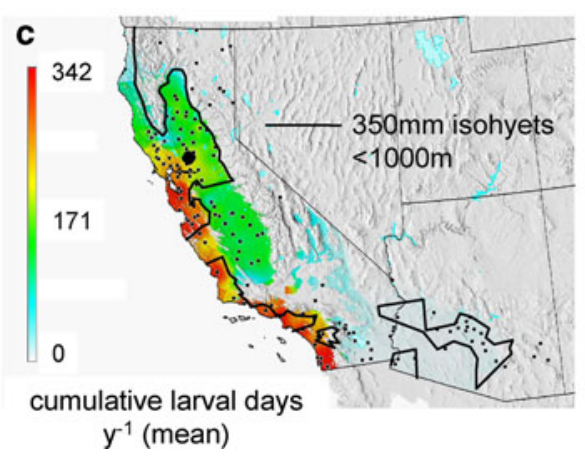

ongoing integrated fruit production program (Walker et al. 1999; Delate et al. 2008).

In contrast, the USDA has classified LBAM as an actionable quarantine pest in California based on estimates of its potential geographic distribution in the United States and projected economic losses to apple, grape, orange and pear crops within this predicted distribution (Fowler et al. 2009; Fig. 7). The potential distribution predicted by Fowler et al. (2009) was modeled using NAPPFAST (North Carolina State University Animal and Plant Health Inspection Service Plant Pest Forecasting System) based on two simple criteria estimated from a 10 years daily climatology database; the frequency of degree days sufficient for the development of three or more LBAM generations, and the frequency of limiting winter temperatures below $-16^{\circ} \mathrm{C}$ for one full day that would preclude winter survival.

Potential geographic distribution and relative abundance of LBAM

It is well accepted that climate plays a major role in limiting the distribution and abundance of species (e.g., Andrewartha and Birch 1954; Brown et al. 1996; Wellington et al. 1999; Gaston 2003). For poikilotherms, temperature has a strong influence on growth and reproduction, and consequently is often a major determinant of geographic distribution.

Many approaches have been used to characterize the favorability of climatic zones for poikilothermic species: comparisons of time series of daily, weekly or monthly temperatures, rainfall, relative humidity, and other variables from the area of origin and the invaded area. A widely accepted approach is the use of physiological indices to estimate the tolerance limits of species to temperature, moisture and other factors (Fitzpatrick and Nix 1968; Gutierrez et al. 1974; Sutherst et al. 1991; Sutherst and Bourne 2009). Davis et al. (1998) called these and related methods the 'climate envelope' approach, and suggested that conclusions may be misleading because higher tropic levels and important temporal factors and events that affect the dynamics and distributional limits of a species are not included.

The weather-driven demographic model used in this study circumvents many of the criticisms raised by Davis et al. (1998), and was used here to map the potential geographic distribution of LBAM in Arizona and California. This approach requires considerably more weather data to drive the model, which increases biological realism and captures important 
Fig. 7 The proposed USDA geographic distribution of favorableness for the establishment of LBAM (from Fowler et al. 2009)

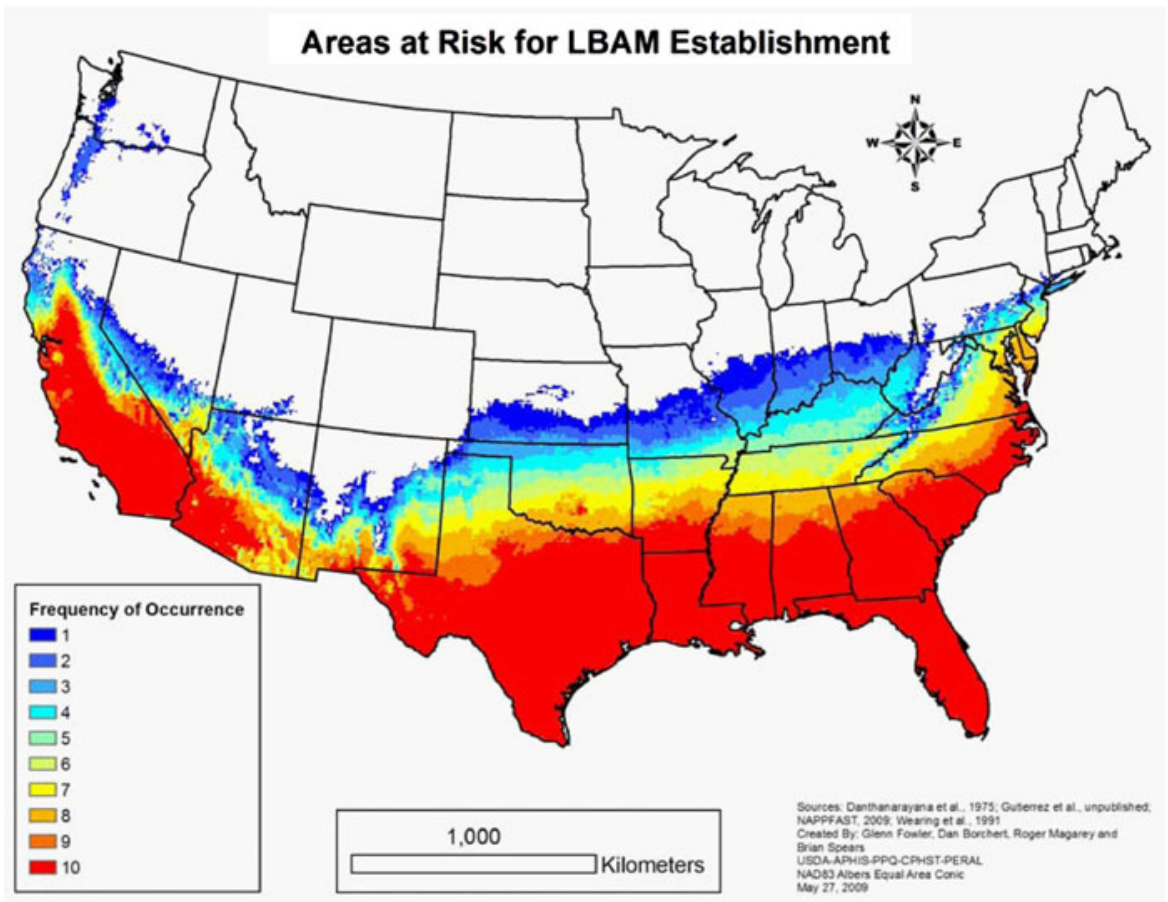

temporal factors that affect the distribution and abundance of a species (e.g., Gutierrez et al. 1994; Gurney et al. 1996; Gutierrez 1996; Holst and Ruggle 1997; Rochat and Gutierrez 2001; Gutierrez and Baumgärtner 1984, 2007).

The developmental biology of LBAM is relatively simple; it lacks an overwintering diapause, it is polyphagous, and its populations are suppressed by a combination of dispersal mortality, extremes of temperature, host plant availability, and in Australia, by native natural enemies that operate in a density independent manner (Danthanarayana and colleagues). This combination of factors is able to keep LBAM populations at a relatively low level of abundance in Australia, except occasionally in irrigated crops where natural enemies are disrupted through use on non-selective insecticides (Geier and Briese 1981). LBAM populations, although currently established in California, remain sparsely distributed and generally low. Here the species is also affected by patterns of temperature and plant availability similar to the patterns in SE Australia, and LBAM in California is also attacked by a suite of native generalist predators and parasitoids (N. J. Mills, unpublished observations).

Using only temperature, our demographic model predicts the distribution of LBAM in California to be restricted largely to near coastal areas with some extension eastward into the northern part of the Central valley (Fig. 5b). The majority of the Central Valley shows less than intermediate favourability due to summer temperatures that exceed the tolerance of LBAM. This suggests that if populations could persist in these areas, the relative abundance of larvae would be lower than those at Davis and approximately onethird the abundance predicted in more favorable coastal areas. The limiting effect of rainfall on the potential distribution of YST, a surrogate annual host plant, reinforces the greater favorability of the coastal regions and further highlights the lack of suitable environmental conditions for LBAM in the southern half of the Central Valley (Fig. 6). These predictions of our demographic model differ markedly from those of the Fowler et al. (2009) model for Arizona and California (Figs. 5, 6 vs. 7). The differences stem primarily from the level of biological detail built into the two models, that of Fowler et al. (2009) being a simple degree-day accumulation model versus our mechanistic simulation model. Our dynamic simulation model has the advantages of incorporating biotic as well as abiotic influences, and daily temperatures rather than weekly, monthly or yearly means, and can more readily track the influence of limiting climatic conditions on LBAM populations. The disparity in 
predictions of the two models also provides support to Sutherst and Maywald (2005) and Sutherst and Bourne (2009), who have highlighted both model structure, and format and choice of climate variables, in influencing predictions of species distributions.

Critics may ask why we have not validated the model by predicting the distribution of LBAM in Australia, and may posit that LBAM is present in

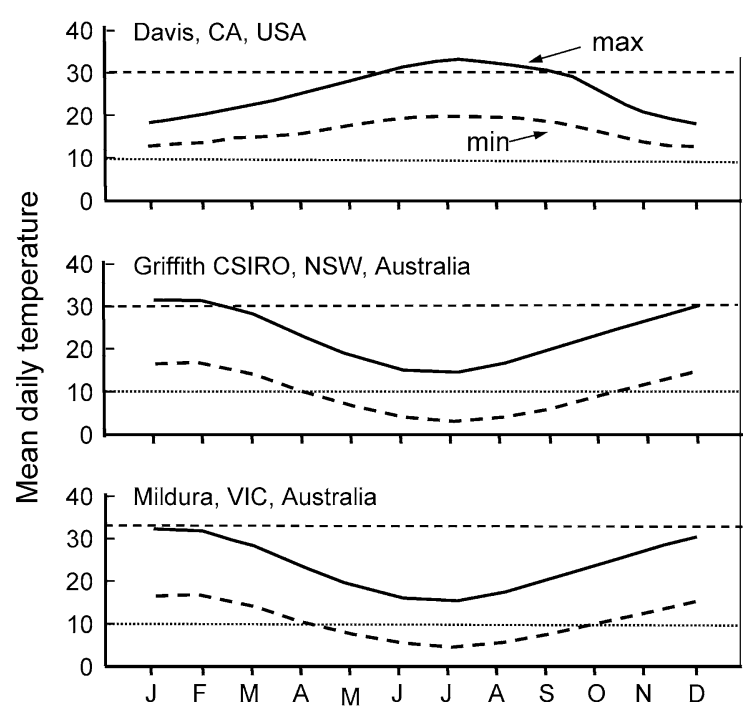

Fig. 8 A comparison of mean daily temperatures for Davis, $\mathrm{CA}$, and two locations in SE Australia (Griffith, NSW and Muldura, VIC) over a 10 years period from $1 / 1 / 1998$ to $1 / 1$ / 2009 regions of Australia that are much hotter than the regions of California that our model predicts as unfavorable. In the absence of sufficient daily climate data to validate the model for the whole country, we examined daily climate data for the period 1/1/19981/1/2009 from five locations in SE Australia (Victoria and New South Wales) where LBAM is known to occur. Mean daily maximum summer temperatures at Mildura (VIC) and Griffith (NSW), the two hottest locations, prove similar to those at Davis, CA, while winter temperatures are lower (Fig. 8). Our model predicts moderate favourability for LBAM at the four hotter inland locations in Australia, as was the case for Davis in California, and greater favourability for the coastal location of Adelaide (Fig. 9). Lloyd et al. (1970) found LBAM infestations were most frequent (and most damaging) in the areas seemingly least favorable for its development, namely cooler southern Victoria and Tasmania. As for the comparison between Davis and Salinas in California (Fig. 4), the relative abundance of LBAM is also predicted to be approximately twice as high in Adelaide as at the inland locations in Australia (Fig. 9).

Any assessment of the pest status of an invasive species must be based on a sound understanding of its likely range of distribution in the new region, in addition to an appraisal of the potential ecological and economic impact that it could have on production and natural ecosystems. The current designation of LBAM as an actionable quarantine pest in the United
Fig. 9 Annual larval days $\mathrm{m}^{-1}$ year $^{-1}$ at five locations in SE Australia for a 10 years period from $1 / 1 / 1998$ to $1 / 1 / 2009$

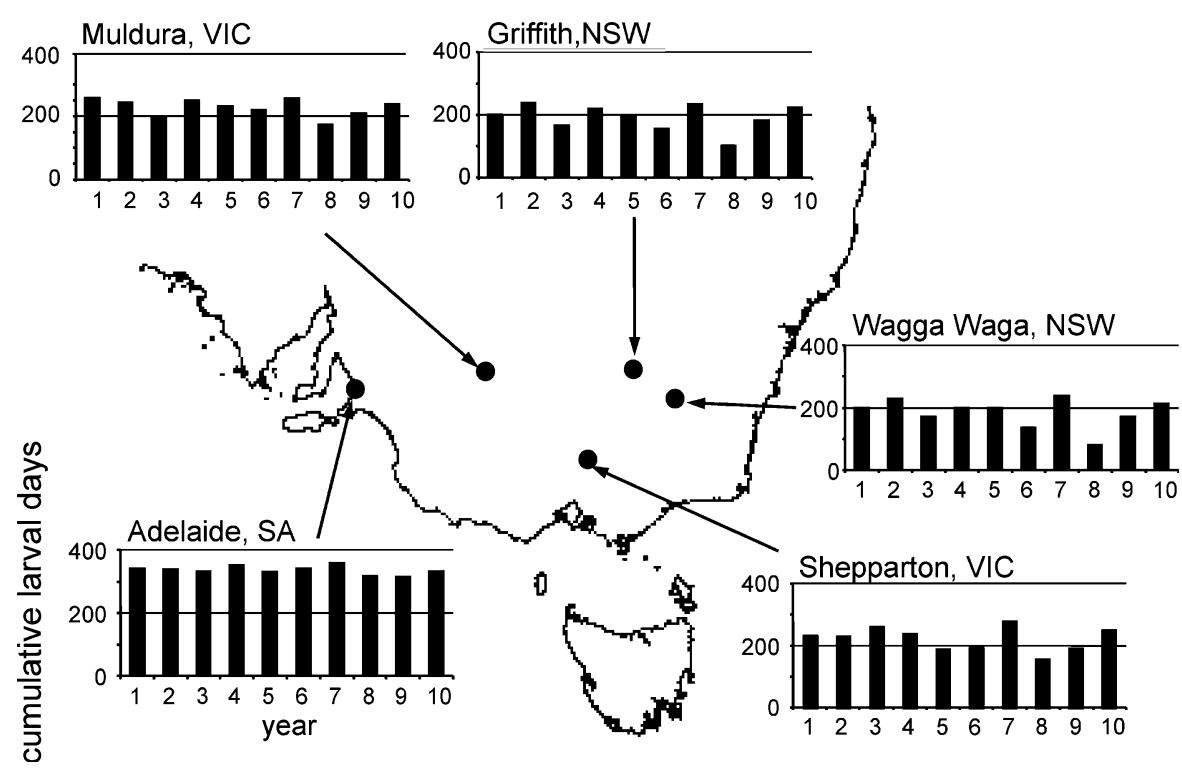


States by USDA is in part based upon the predicted distribution of Fowler et al. (2009). The strong decline in favourability from coastal to interior regions of California and its likely absence from Arizona, as predicted by our model, question the accuracy of the USDA assessment of risk to production and natural ecosystems and suggest the need for re-evaluation of the current pest status of LBAM in the United States.

Open Access This article is distributed under the terms of the Creative Commons Attribution Noncommercial License which permits any noncommercial use, distribution, and reproduction in any medium, provided the original author(s) and source are credited.

\section{References}

Andrewartha HG, Birch LC (1954) The distribution and abundance of animals. University of Chicago Press, Chicago

Bartell RJ, Lawrence LA (1973) Reduction in responsiveness of males of Epiphyas postvittana (Lepidoptera) to sex pheromone following previous brief pheromonal exposure. J Insect Physiol 19:845-855

Brown JW (2007) Discovery of light brown apple moth in North America. http://www.tortricidae.com/TORTS_newsletter $8 \% 282 \% 29$.pdf

Brown JH, Stevens GC, Kaufman DM (1996) The geographic range: size, shape, boundaries and internal structure. Annu Rev Ecol Syst 27:597-623

Buckley YM (2008) The role of research for integrated management of invasive species, invaded landscapes and communities. J Appl Ecol 45:397-402

Coetzee JA, Hill MP, Schlange D (2009) Potential spread of the invasive plant Hydrilla verticillata in South Africa based on anthropogenic spread and climate suitability. Biol Invasions 11:801-812

Danthanarayana W (1975) The bionomics, distribution and host range of the light brown apple moth, Epiphyas postvittana (Walk.) (Tortricidae). Aust J Zool 23:419-437

Danthanarayana W (1976a) Diel and lunar flight periodicities in the light brown apple moth, Epiphyas postvittana (Walker) (Tortricidae) and their possible adaptive significance. Aust J Zool 24:65-73

Danthanarayana W (1976b) Flight threshold and seasonal variations in flight activity of the light brown apple moth, Epiphyas postvittana (Walk.) (Tortricidae), in Victoria, Australia. Oecologia 23:271-282

Danthanarayana W (1976c) Environmentally cued size variation in the light-brown apple moth, Epiphyas postvittana (Walk.) (Tortricidae), and its adaptive value in dispersal. Oecologia 26:121-132

Danthanarayana W (1983) Population ecology of the light brown apple moth, Epiphyas postvittana (Lepidoptera: Tortricidae). J Anim Ecol 52:1-33

Danthanarayana W, Gu H, Ashley S (1995) Population growth potential of Epiphyas postvittana, the lightbrown apple moth (Lepidoptera: Tortricidae) in relation to diet, temperature and climate. Aust J Zool 43:381-394

Davis AJ, Jenkinson LS, Lawton JH, Shorrocks B, Wood S (1998) Making mistakes when predicting shifts in species range in response to global warming. Nature 391:783-786

Delate K, McKern A, Turnbull R, Walker JTS, Volz R, White A, Bus V, Rogers D, Cole L, How N, Guernsey S, Johnston J (2008) Organic apple production in two humid regions: comparing progress in pest management strategies in Iowa and New Zealand. Hortic Sci 43:12-21

DiCola G, Gilioli G, Baumgärtner J (1999) Mathematical models for age-structured population dynamics. In: Huffaker CB, Gutierrez AP (eds) Ecological entomology, 2nd edn. Wiley, New York, pp 503-531

Dumbleton LJ (1932) The apple leaf roller (Tortrix postvittana Walker). NZ J Sci Technol 14:83-92

Dumbleton LJ (1939) Contribution to the physical ecology of Tortrix postvittana, Walk. (Lep.). Bull Entomol Res 30: 309-319

Evans JW (1937) The light-brown apple moth (Tortrix postvittana, Walk.). Tasman J Agric 8:125-128

Fitzpatrick EA, Nix HA (1968) The climatic factor in Australian grasslands ecology. In: Moore RM (ed) Australian grasslands. Australian National University Press, Canberra, pp 3-26

Fowler G, Garrett L, Neeley A, Margarey R, Borchert D, Spears B (2009) Economic analysis: risk to U.S. apple, grape, orange and pear production from the light brown apple moth, Epiphyas postvittana (Walker). USDAAPHIS-PPQ-CPHST-PERAL, 28 pp

Gaston KJ (2003) The structure and dynamics of geographical ranges. Oxford University Press, Oxford

Geier PW (1965) Conditions of management of two orchard pests, one exotic and the other native to South-Eastern Australia. In: Proceedings of 12th International Congress of Entomology 1964, p 598

Geier PW, Briese DT (1979) The light-brown apple moth, Epiphyas postvittana (Walker): 3. Differences in susceptibility to a nuclear polyhedrosis virus. Aust J Ecol 4:187-194

Geier PW, Briese DT (1980) The light brown apple moth Epiphyas postvittana (Walker): 4. Studies on population dynamics and injuriousness to apples in the Australian Capital Territory. Aust J Ecol 5:63-95

Geier PW, Briese DT (1981) The light-brown apple moth, Epiphyas postvittana (Walker): a native leafroller fostered by European settlement. In: Kitching R, Jones R (eds) The ecology of pests. CSIRO, Melbourne, pp 131-155

Geier PW, Briese DT, Lewis T (1978) Light-brown apple moth, Epiphyas postvittana (Walker). 2. Uneven sexratios and a condition contributing to them in the field. Aust J Ecol 3:467-488

Gu H, Danthanarayana W (1990a) Age-related flight and reproductive performance of the light brown apple moth, Epiphyas postvittana. Entomol Exp Appl 54:109-115

$\mathrm{Gu}$ H, Danthanarayana W (1990b) The role of availability of food and water to the adult Epiphyas postvittana, the light brown apple moth, in its reproductive performance. Entomol Exp Appl 54:101-108

Gu H, Danthanarayana W (1992) Influence of larval rearing conditions on the body size and flight capacity of Epiphyas postvittana moths. Aust J Zool 40:573-581 
Gurney WSC, Middleton DAJ, Nisbet RM, McCauley E, Murdoch WW, De Roos A (1996) Individual energetics and the equilibrium demography of structured populations. Theor Popul Biol 49:344-368

Gutierrez AP (1996) Applied population ecology: a supplydemand approach. Wiley, New York

Gutierrez AP, Baumgärtner J (1984) Multitrophic level models of predator-prey energetics: II. A realistic model of plantherbivore-parasitoid-predator interactions. Can Entomol 116:933-949

Gutierrez AP, Baumgärtner J (2007) Modeling the dynamics of tritrophic population interactions. In: Kogan M, Jepson P (eds) Perspectives in ecology and integrated pest management. Cambridge University Press, Cambridge, pp 301-360

Gutierrez AP, Nix HA, Havenstein DE, Moore PA (1974) The ecology of Aphis craccivora Koch and Subterranean Clover Stunt Virus in south-east Australia. III. A regional perspective of the phenology and migration of the cowpea aphid. J Appl Ecol 11:21-35

Gutierrez AP, Mills NJ, Schreiber SJ, Ellis CK (1994) A physiologically based tritrophic perspective on bottom up-top down regulation of populations. Ecology 75:22272242

Gutierrez AP, Pitcairn MJ, Ellis CK, Carruthers N, Ghezelbash R (2005) Evaluating biological control of yellow starthistle (Centaurea solstitialis) in California: a GIS based supply-demand demographic model. Biol Control 34: 115-131

Gutierrez AP, Daane KM, Ponti L, Walton VM, Ellis CK (2008) Prospective evaluation of the biological control of vine mealybug: refuge effects and climate. J Appl Ecol 45:524-536

Holst N, Ruggle P (1997) A physiologically based model of pest-natural enemy interactions. Exp Appl Acarol 21: 325-341

Lawrence LA, Bartell RJ (1972) The effect of age on calling behaviour of virgin females of Epiphyas postvittana (Lepidoptera) and on their pheromone content and ovarian development. Entomol Exp Appl 15:455-464

Levine JM, Vila M, D'Antonio CM, Dukes SJ, Grigulis K, Lavorel S (2003) Mechanisms underlying the impacts of exotic plant invasions. Proc R Soc Lond B Biol Sci 270: $775-781$

Lloyd NC, Jones EL, Morris DS, Webster WJ, Harris WB, Lower HE, Hudson NM, Geier PW (1970) Managing apple pests: a new perspective. J Aust Instit Agric Sci: 251-258

MacLellan CR (1973) Natural enemies of the light brown apple moth, Epiphyas postvittana, in the Australian Capital Territory. Can Entomol 105:681-700
Migeon A, Ferragut F, Escudero-Colomar LA, Fiaboe K, Knapp M, de Moraes GJ, Ueckermann E, Navajas M (2009) Modelling the potential distribution of the invasive tomato red spider mite, Tetranychus evansi (Acari: Tetranychidae). Exp Appl Acarol 48:199-212

Parker IM, Simberloff D, Lonsdale WM, Goodell K, Wonham M, Kareiva PM, Williamson MH, Von Holle B, Moyle PB, Byers JE, Goldwasser L (1999) Impact: toward a framework for understanding the ecological effects of invaders. Biol Invasions 1:3-19

Pimentel D, Lach L, Zuniga R, Morrison D (2000) Environmental and economic costs of nonindigenous species in the United States. Bioscience 50:53-65

Powell JA (1983) Expanding geographical and ecological range of Platynota stultana in California (Lepidoptera: Tortricidae). Pan-Pac Entomol 59:233-239

Powell JA (1997) Occurrence of the Palaearctic moth, Cnephasia longana (Tortricidae), on Santa Rosa Island, California. J Lepid Soc 51:93-95

Rochat J, Gutierrez AP (2001) Weather mediated regulation of olive scale by two parasitoids. J Anim Ecol 70:476-490

Rodda GH, Jarnevich CS, Reed RN (2009) What parts of the US mainland are climatically suitable for invasive alien pythons spreading from Everglades National Park? Biol Invasions 11:241-252

Suckling DM, Brockerhoff EG (2010) Invasion biology, ecology, and management of the light brown apple moth (Tortricidae). Annu Rev Entomol 55:285-306

Sutherst RW, Bourne AS (2009) Modelling non-equilibrium distributions of invasive species: a tale of two modelling paradigms. Biol Invasions 11:1231-1237

Sutherst RW, Maywald G (2005) A climate-model of the red imported fire ant, Solenopsis invicta Buren (Hymenoptera: Formicidae): implications for invasion of new regions, particularly Oceania. Environ Entomol 34:317-335

Sutherst RW, Maywald GF, Bottomly W (1991) From CLIMEX to PESKY, a generic expert system for risk assessment. EPPO Bull 21:595-608

Vansickle J (1977) Attrition in distributed delay models. IEEE Trans Syst Manage Cyber 7:635-638

Walker JTS, Wearing CH, Bradley SJ, Shaw PW, Burnip GM, Tomkins AR, Richardson CA Hodson AJ (1999) Integrated fruit production (IFP) for New Zealand pipfruit: evaluation of pest management recommendations. In: Proc 51st NZ Plant Protection Conference, pp 166-172

Wellington WG, Johnson DL, Lactin DJ (1999) Weather and insects. In: Huffaker CB, Gutierrez AP (eds) Ecological entomology, 2nd edn. Wiley, New York, pp 313-353 